\title{
INDUSTRIAL REVOLUTIONS AND ITS EFFECTS ON QUALITY OF LIFE
}

\section{DOI: 10.17261/Pressacademia.2019.1109 \\ PAP-V.9-2019(56)-p.304-311}

Tayfun Caglar Koc ${ }^{1}$, Suat Teker ${ }^{2}$

${ }^{1}$ World Bank, International Finance Corporation, Vien, Austuria. tkoc@ifc.org, ORCID: 0000-0002-1098-4328

${ }^{2}$ Işık University, Maslak Campus, Sariyer, Istanbul, Turkey. suat.teker@isikun.edu.tr, ORCID: 0000-0002-7981-3121

To cite this document

Koc, T., Teker, S., (2019). Industrial Revolutions and its effects on quality of life. PressAcademia Procedia (PAP), V.9, p.304-311

Permemant link to this document: http://doi.org/10.17261/Pressacademia.2019.1109

Copyright: Published by PressAcademia and limited licenced re-use rights only.

\begin{abstract}
Purpose- This paper intends to put forward the historical perspectives of industrial revolutions and analyze the effcets of revolutions on the quality of life.

Methodology- This research uses a review and analysis approach for the historical evolment of industrial revolutions in general.

Findings- All industrial revolutions strongly affected the quality of life of people. However, the industry 4.0 has completely changed the way of living for every single paty, e.g. businesses, governmets, people.

Conclusion- The new definition of internet-of-things looks to rule the new order of competetiveness in the World. The jobs have been recenly created we never imagined ten years ago. Most jobs have started to disappear we never thought about. Technological innovation and advancement activities have a significant impact on international competitiveness.
\end{abstract}

Keywords: High technology, industrial revolutions, industry 4.0, quality of life.

JEL Codes: O30, O31, 033

\section{INTRODUCTION}

The critical role of history here is to characterize the complexity of how revolutions change the world order. Arguably most important is the understanding of the dynamics of the revolutions that examine its historical developments can make it uniquely complicated, but it is valuable to create a roadmap. It is complicated as it contains education, science, manufacturing, capital intensity, technological advances/innovations, and efficiency. In order to understand the rapidly changing world, it will be extremely beneficial to recognize and discuss the ideas of Alvin Toffler

Toffler creates a framework which is starting from the first periods of the history up to the present day and draws attention to the benefit of the system understanding by making projections about the future. Human history has undergone three significant paradigm transitions, and these are described with the waves metaphor by a well-known sociologist and philosopher Alvin Toffler. Human history has undergone three significant paradigm transitions, and these are described with the waves metaphor by a well-known sociologist and philosopher Alvin Toffler; the agricultural revolution which is the first nascent point of the wave has emerged after the Neolithic period of human history. The humankind spent thousands of years in the first wave. The most critical transition event in the society of the agricultural period, the huntergatherer way of life was transferred to be a farmer(producer); therefore, the history of humanity was moved from pre-history to civilization. People have learned to live together. They discovered the advantages of living together. Along with their coexistence, the concept of property emerged, and the foundations of fundamental rules and laws were established. While spending a plenty amount of time in the First Wave, the rate of economic growth was unsatisfied for the development, and the range of inequality in the living standards was not swiftly widening in that period.

The second part of the wave which is described as an industrial revolution began around 1750s in England and spread to other countries in the European continent. The essence of the industrial revolution is examined as the phenomenon that made a remarkable effect on the manufacturing system. Economic development became very quick; national markets were created, new network systems was formed since technological developments were entirely implemented into the industries; steam power, railroads, electrification, and assembly line. So instead of insisting for a keeping paradigm approach, established a significant number of factory and industries, focused on scientific for doing efficient business models and inventions, social and cultural life moved from agricultural life to manufacturing life for rationalism, mechanization and mass production. 
The third extension arm is the "internet age" which is based on the knowledge power. In the information society, the number of employees in the information sector exceeded the number of employees in the industrial area, and the production of information and knowledge has become the essential element of creating value. It facilitated the transmission of knowledge, accelerated social change, and most importantly increased the impact of the change, so it has been causing various crises and pains for those who do not understand the requirement of this period. Toffler considered the development of societies so far in three main Wave Theory. All three of these waves have created new lifestyles or a new way of doing business models that would not come to mind even earlier generations (Toffler, 1981).

Technological developments that gained momentum after the industrial revolution became the most important driving force of the economy and growth. Countries that produce technology and use this technology most efficiently are at the forefront of the economic growth process, and the countries that do not catch the pace of technological development are left behind in this race. Therefore, it is essential to emphasize how the industry developed throughout history through technological developments.

This paper is organized in 4 parts. The following section cover the histroy of industrial revolutions. The later part largely examines the industry 4.0. Next part explains how new Technologies improve the quality of life. The final section presents the concluding remarks.

\section{HISTORY OF INDUSTRIAL REVOLUTIONS}

It is beneficial to examine the Industrial Revolution as it has contributed a vital capacity for economic developments. In fact, traditional production industries are the driving power of today's digital and artificial intelligence production system with the exponentially growing technologies. In order to emphasize the power of economic development and competitiveness and why countries and their manufacturing systems need to adapt or closely follow technological progress? In every period, the different type of technology inventions made an impact on the countries' economic improvement or declines. Technology development activities led to economic development by enhancing labor productivity, and new technologies enable each worker to contribute a more considerable number of outcomes and services.

- Industry Revolution 1.0; The invention of the James Watt's steam power representing clearly as an indicator or start point of Industry Revolution 1.0 in the world history, and it is the most well-known information about for this period.

- Industry Revolution 2.0; Henry Ford's assembly line triggered paradigm change in the history of the manufacturing process. The model $\mathrm{T}$ was the first automobile on the assembly line, thus producing less expensive cars to the world and creating higher wage jobs in the market.

- Industry Revolution 3.0; It is an entirely different period when computer technology used as an interface. In this period, the importance of human power diminished, and the speed of production increased considerably through computer systems.

- Industry Revolution 4.0; Cyber-Physical-Systems is about the constant development of knowledge and information system in blending with an uncontrollable increase of computing, transmission, and storage capacity, it facilitates the evolution of frequently strong, interconnected new technological operations. This new capability, devices can communicate with several other machines and with the manufacturers to perform whatever people now describe as a "cyber-physical production system" (CPPS).

Figure 1: Stages of Industrial Revolutions

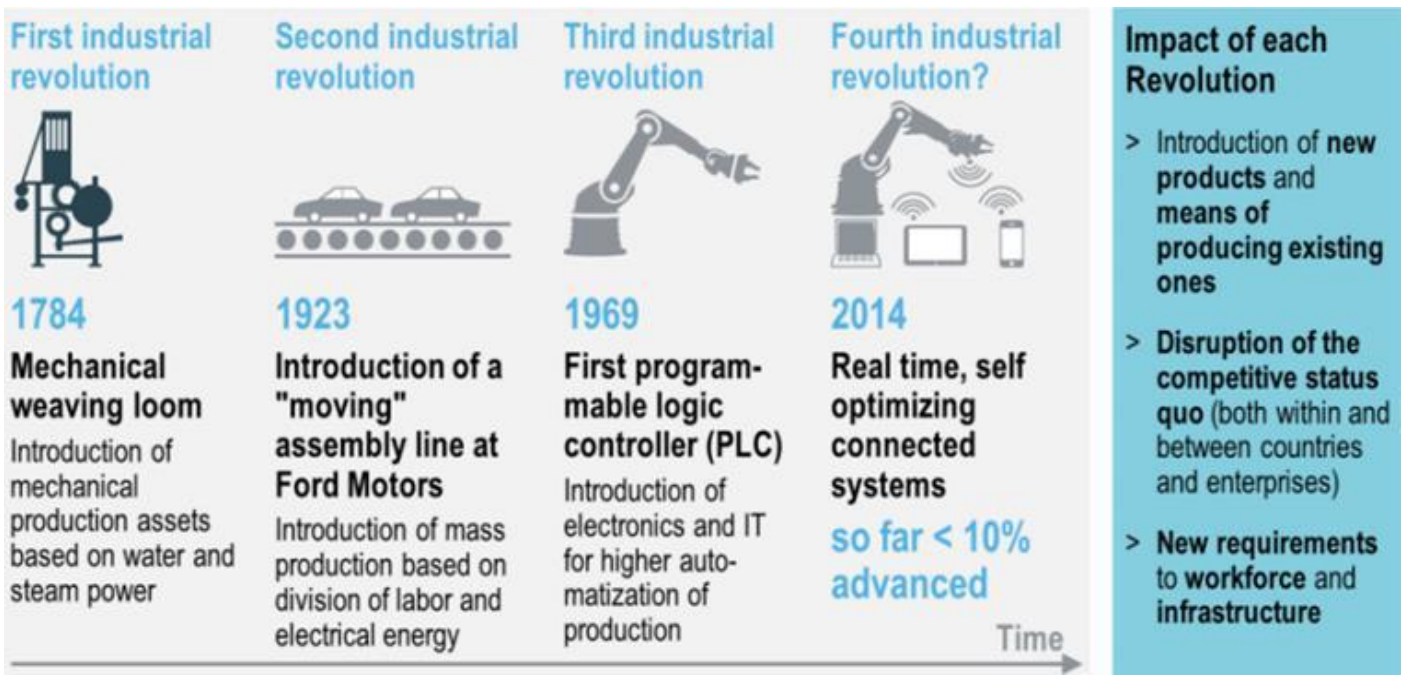

Source: http://www.globalskillsummit.com/whitepaper-summary.pdf, Accessed at: 12.12.2018.

It is unquestionable that modern societies and developments are owe everything to industrial revolutions. The engine of the industrial transformation began with the mechanical production powered by the steam in the 18th-century. Second development which is mass production assembly lines requires labor and electrical energy have the light gas to the engine in the 19th-century. With the automated production using electronics is accelerated the engine in the 20th century. Today, the engine has been working fabulously fast and digital since everything is connected to each other via wireless and internet in the 21st century. 


\section{INDUSTRY REVOLUTION 4.0}

The fourth industrial revolution can be labeled as the advent of "cyber-physical systems," it would not be wrong to say that this development symbol of the fourth wave and it involved entirely new capabilities for people and machines. Cyber-Physical-Systems is about the constant development of knowledge and information system in blending with an uncontrollable increase of computing, transmission, and storage capacity, it facilitates the evolution of frequently strong, interconnected new technological operations. These new capable devices can communicate with several other machines and with the manufacturers to perform whatever people now describe as a "cyber-physical production system" (CPPS). A good definition is addressed by Kagermann et al. (2013) "include embedded systems, production, logistics, engineering, coordination and management processes as well as internet services, which by courtesy of sensors directly collect physical data and utilizing actuators influence physical procedures. These systems are interconnected via digital networks, use worldwide available data and services and are equipped with human-machine interfaces. Cyber-Physical-Systems are open socio-technical systems, which enable several novel functions, services and capabilities." (Bartodziej, 2016).

Along with the quick shifts in the era of information and communication technologies (ICT) have destroyed the invisible boundaries between virtual reality and the present world. The primary concept behind Industry 4.0 is to construct a social network "anywhere" machines enable to communicate with several other machines at the same time, it is named under the Internet of Things (IoT) and for people, named the Internet of People (IoP). All adverse developments help manufacturers integrate the actual labor-oriented system right into a virtual system, artificial intelligence and enable organizations to collect dynamic valid data, interpret them, and even make decisions based on unexpected events. This transformation has a compelling right to speak to make changes in the production technology, social life, economy and education system. In this part, the concept which is described by German's Industry 4.0 is examined in details. This time revolution has emerged from the German government's announcement under the "strategic initiative" headline Industry 4.0 in January 2011. Industry Revolution 4.0 actualized by the Communication Promoters Group of the Industry-Science Research Alliance. The German government has been adopting a High-Tech Strategy for research and innovation studies against the problems of climate/energy, health/food, mobility, security, and communication. Besides, within the new smart manufacturing development, Industry Revolution 4.0 is created own motto "smart thinking" approach in manufacturing environments. (Bartodziej, 2016). With the Smarty Factory concept, an interconnected world which established on the Internet of Things and Services would be the vital economic actors who changed into intelligent infrastructures and planets. This transformation has been increasing the interest in the emergence of smart grids and intelligent or intelligent buildings in the field of energy supply.

\section{Figure 2: Smart Factory in the Center of the Concept of Industry 4.0.}

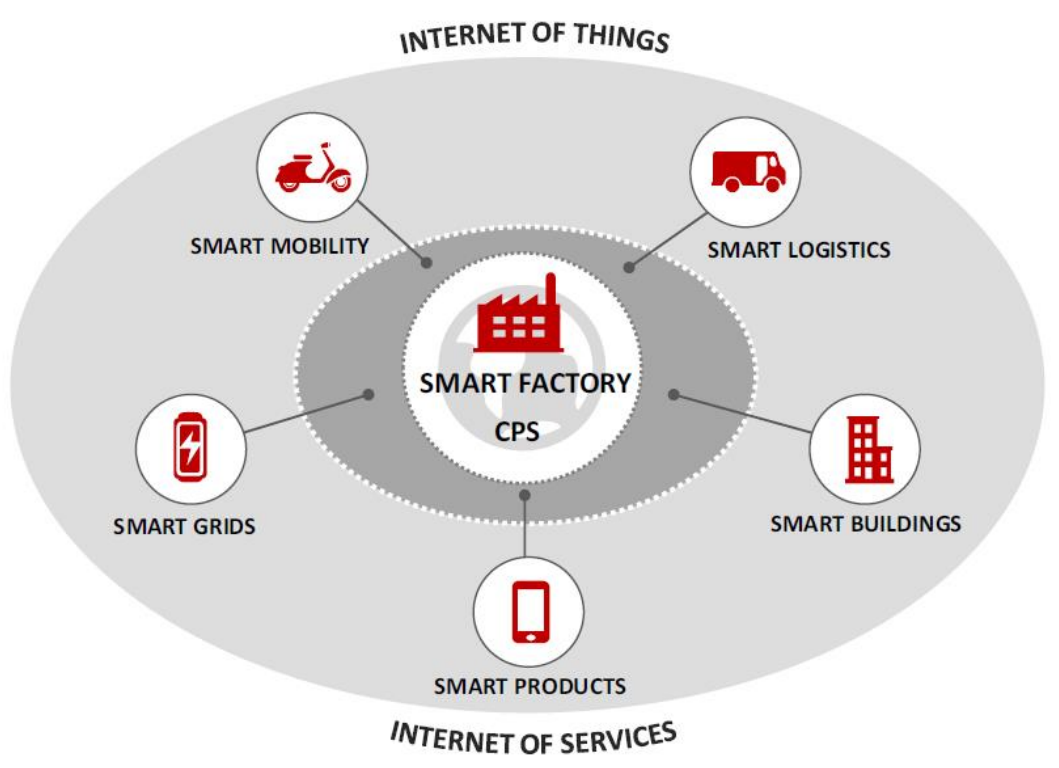

Source: Kagermann, H., Helbig, J., Hellinger, A., \& Wahlster, W. (2013). Recommendations for implementing the strategic initiative INDUSTRIE 4.0: Securing the future of German manufacturing industry; final report of the Industrie 4.0 Working Group. Forschungsunion.

Primary, the dynamics of the idea will be considered followed by an explanation of what is meant by this new revolution, potentials, and international approaches. Afterward, the meaning of an end-to-end digital integration within a Smart Factory will be described in simple language. The basic framework of Industry Revolution 4.0 is an approach that aims to maximize computerization in the manufacturing industry via high technology production equipment. There are five primary goals for this period (Egilmez, 2018);

1. The reduction the number of human labor in the production, thus human mistake rate diminishes automatically at the same parallel,

2. To obtain maximum flexibility in the production line to produce exceptional products when requested by the customer,

3. Acceleration of the production process,

4. Increase communication channels between produces and consumer, 
5. To create tracking capability on the waiting period of the order process.

The manufacturing industry is related to significant structural transition due to global demands. It is important to point out that several ongoing developments of Industrial Revolution 4.0, which substantially influenced the entire manufacturing products which include; cloud computing, advanced analytics, mobile computing, machine-to-machine communication, advanced robotics, community platforms, 3D printing, optical Technologies, microsystems technology, nanotechnology, biotechnology. Therefore, these new products have been drawing entrepreneurs' attention to make an investment on the cornerstones for future productions, embedded systems, smart objects, Smart Factory, robust networks, cloud computing, and IT-security. For this reason, the new emerged, interconnected value chains changed the traditional way of doing business models and organizations structure because of the incredible potential of the fourth industrial revolution for the entire manufacturing environment is candescent. Hereupon, the technology has gained utterly new meaning for the modern life and for those who intended to be high technology producer (Bartodziej, 2016);

1. Data, computational power, and connectivity (e.g., wireless networks),

2. Analytics and Intelligence (e.g., artificial intelligence of objects),

3. Human-machine interaction (e.g., augmented reality (AR) solutions),

4. Digital-to-physical conversion (e.g., 3D printing).

History always proofs itself that consumers intend to gain new capability from industrial revolutions as the cost of goods downs while quality increases, and it remains this is the entirely accurate idea for the latest.

As Schwab writes (Davis, 2016), "The new technology age if shaped responsively and responsibly, could catalyze a new cultural renaissance that will enable us to feel part of something much larger than ourselves - a truly global civilization... We can use the Fourth Industrial Revolution to lift humanity into a new collective and moral consciousness based on a shared sense of destiny".

Industry Revolution 4.0 is distinguished as a theory endowed by German institutions, organizations, and companies to guarantee and strengthen Germany's active competitive status in various industrial fields. Industry 4.0 is often practiced as a metonym for the fourth industrial revolution in Germany. The whole potential of the fourth industrial revolution for the entire manufacturing conditions still is robust to figure out; however, it is examined massive depending on the sector. In various other circumstances, there are related strategies (particularly in the US), which also continue the development of its industries. These strategies, on the one hand, can be recognized as a challenge, when the involved actors work for the preeminent position in the world.

\section{Figure 3: Automation Percentages for Countries}

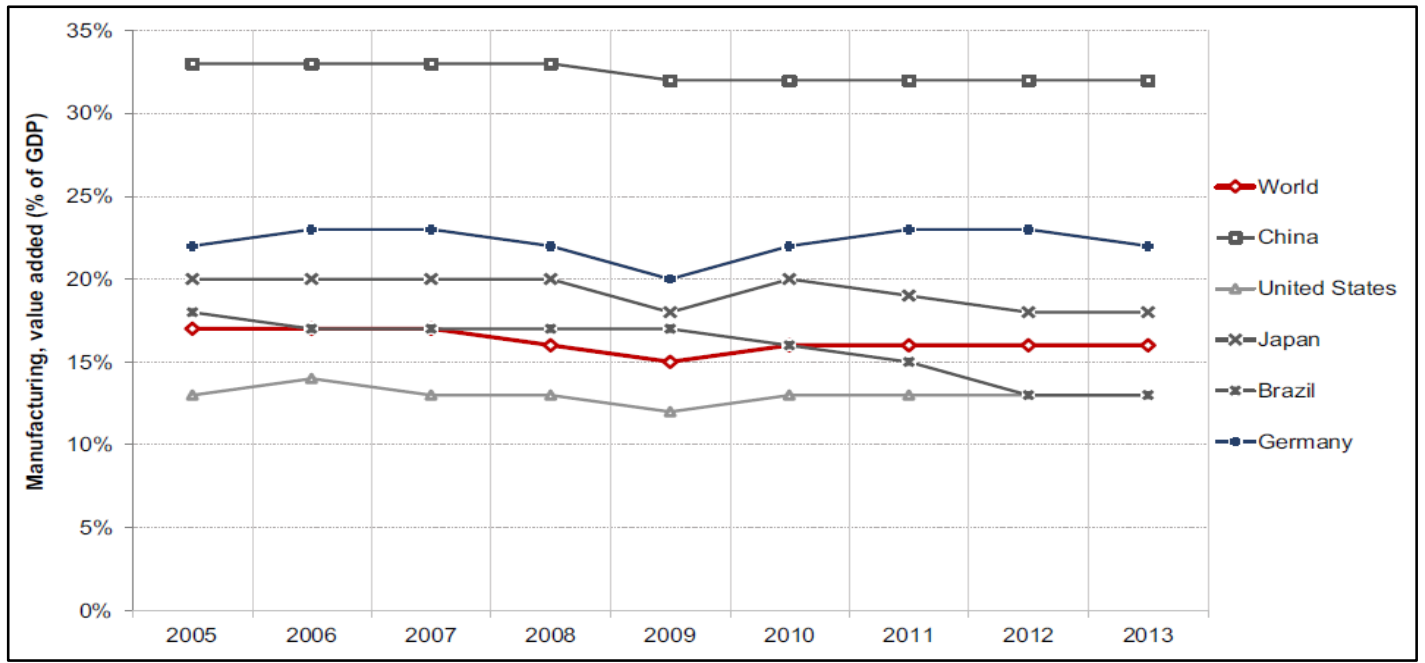

Source: Worldbank, 2015.

The evolution of the fourth revolution is predominantly operated by new business requirements such as volatility, flexibility, and individualization as well as via technological innovations. The combination of new technologies such as Cyber-Physical Systems and Internet of Services within industrial processes allows entirely new opportunities such as new business standards and business institutions. Due to the wide-ranging ingredients of the concept Industry Revolution 4.0 and its indications, the aim is wholly established on the technologies, which allow the transformation of a fourth industrial revolution.

The process of industrialization movement started with the foundation of mechanical manufacturing material and equipment at the end of the 18th century. The advancement of the enables it to the steam engine by James Watt, machines and engines reformed the way goods were produced. The paradigm transition from an agricultural to an industrial civilization has emerged. The first industrial revolution performed an enormous benefaction to the reduction of "famine catastrophes" in industrial-oriented countries or societies and, concurrently, to the resulting growth of a population explosion. This revolution was followed by a second industrial revolution that established approximately the turn of the 20th century and linked electrically machine powered mass production of goods based on the 
division of labor. This revolution predominantly invented by organizational changes such as the invention of Henry Ford's assembly line and the scientific management methods based on Frederic W. Taylor, famously known as Taylorism. The large-scale industrial mass production increased and mainly developed in chemical and electronics industry as well as in mechanical engineering and automotive industry production. This advancement was followed by the third industrial revolution that rose during the beginning of the 1970 s and has remained valid up to the 2000s.

The Industry Revolution 3.0 was shaped around the development of digital electronics and information technology for programmable automation. Hence, an indispensable result of this transformation had remarkable socio-economic and socio-cultural impressions, namely a high degree of rationalization in the organizations. However, the reliable productivity of manufacturing processes enhanced due to the installation of serial production systems. The third wave is still an ongoing present, but it is sleekly changing right into a new era of industrialization - the fourth industrial revolution. The Fourth Industrial Revolution is critical to recognize because it does not just affect "manufacturers' interest" - it affected all of us. While Industry 4.0 has expanded to surround the business operations, the workforce and society itself, it is standing at the heart of the supply chain and manufacturing compound the cornerstone of the world as we understand it on today's world. Industry revolution 4.0 did not start and last with only supply chain or product developments. Its influence could be much more extensive, touching every industry and business, even societies and lifestyles. Industry Revolution 4.0 capacities can enhance business processes and revenue increase, changing products, and customer experience. The alliance of digital and physical technologies would change how clients, users, employees, and other third parties of the industry aspect demand to experience and communicate with an organization. The organizations that concentrated on the production and evolution of information. The consequences of Industry Revolution 4.0 can be touched at various business levels: across whole ecosystems, at the organizational level, and the private operator and customer level. On the other hand, should indicate one more significant point for those who late for Industry Revolution 4.0. The growth of smart intelligence and omnipresent, logical systems in the era of Industry 4.0 resembles to proclaim a change in what kind of companies will have the concern of their workers: what abilities they require for the new period, what responsibilities need to be performed, even what positions would be alive (Kagermann et al., 2013). Nevertheless, current many job descriptions may inevitably resemble the loss of jobs all around the world. The United Kingdom or the US are good examples for this issue, technological developments created to create 3.5 million new businesses opportunity between 2001 and 2015, indeed while it caused to the loss of 800,000 in the fourth wave or 47\% of US jobs will disappear because of automation or computerization (Mahdawi, 2017). It merely says that smart intelligence will serve many essential tasks. Unfortunately, Industry Revolution 4.0 can both enable and challenge workers to do much more things. Many jobs will entirely disappear because; many will directly redefine with the technology. Therefore, people will likely face a lack of required skill problems for new conditions or be out of work circle by 2030 . If you do not educate your children according to the requirements of the new period, robots will take our children's job!

Figure 4: Automation Percentages in Jobs

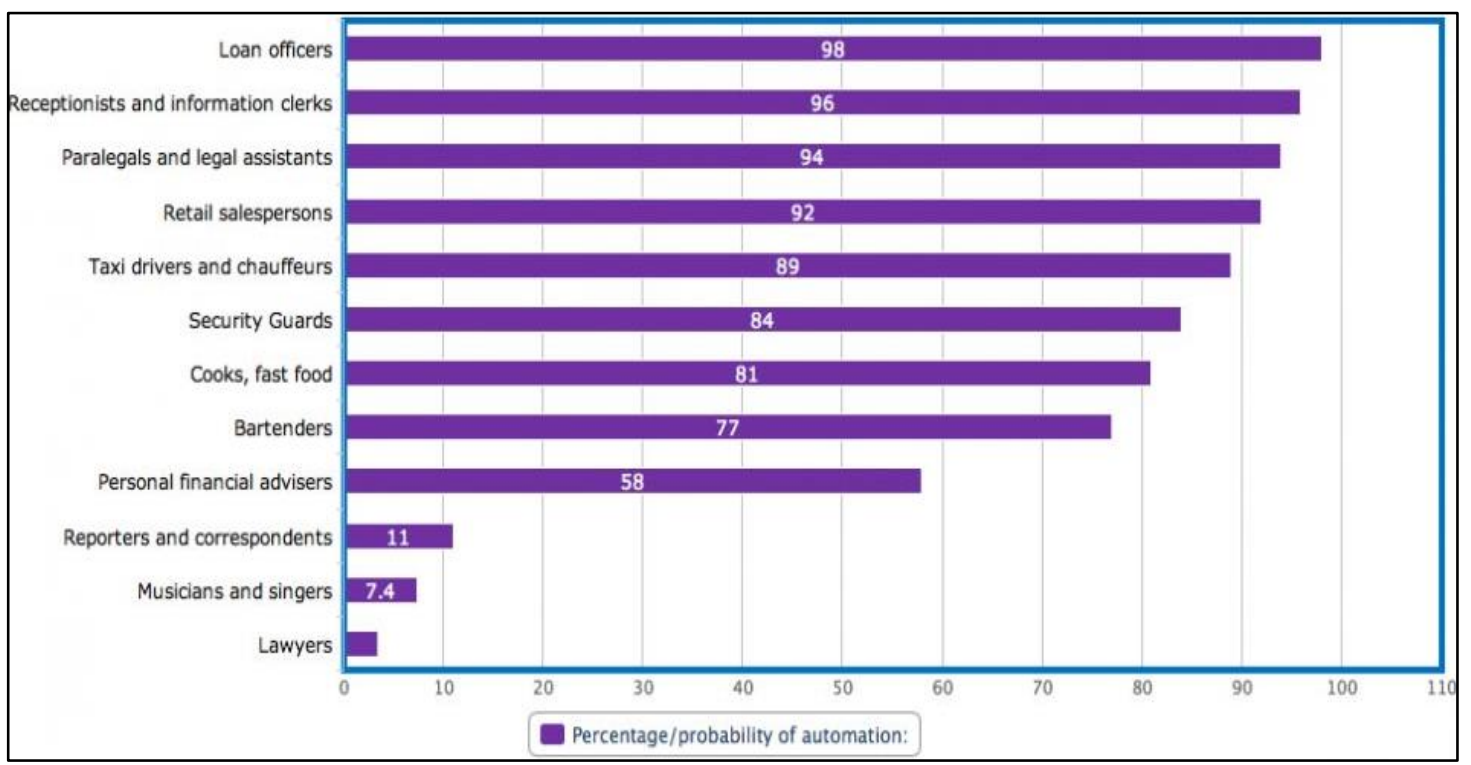

Source: https://www.businessinsider.de/likelihood-of-your-job-being-taken-over-by-robots-2016-8?r=US\&IR=T, Accessed at: 12.12 .2018 .

\section{NEW TECHNOLOGY FOR QUALITY OF LIFE}

As examined the importance of shifting from primitive life to civilization in the previous part, it now points out very significant driving power in people's lives to make more accessible this paradigm transition. The world named this driving power as a "technology." Correspondingly, emerging of technology has been one of the dominant parts in shaping civilization especially for the modern life. The primary meaning of technology is to enable multiple tasks in our daily lives, indeed; also can define technology as new products and processes utilized to oversimplify our daily lives. People use technology to increase their abilities, which makes people the essential part of any technology. Technology is part an application of science handled to resolve problems. However, it is vital to understand that technology and science are 
separate subjects, which work hand-in-hand to perform specific tasks. People use technology in nearly everything they do in our daily lives; they use technology at the office, they use technology for communication, transportation, e-learning, manufacturing, securing data and scaling businesses (Ramey, 2013). Technology has the ridiculous dynamism to change people's lives, help economic development rate, and produce opportunities for individuals, businesses, and nations throughout the world. In this point, it is critical that to understand how people develop technology and how technology products or developments shape people's communications with individually, thus the real world is related not only for those who work for the new capability. Technology is all around us: it is in progress and creates opportunity all people for those who use their daily and produce who intend to contribute to humanity. Examined mostly technology developments which developed after the industrial revolution and today. Although early people and their relatives experienced various natural rules and improved abilities for inventing helpful tools for hunting and gathering, it would be a wrong approach to described them as the first inventors. Since their inventions, mathematical rules, cured illnesses, built great structures, created new materials, and learned how to read the stars and planets were not based on science. Technological development or inventions is about delivering capability to answer a human necessity or requirements rather than merely understanding what is happing all around the natural world, which is the aim of science. Therefore, the invention of the wheel deserves respects in the world history as indicated by Jerome S. Meyer "Man's first invention, and one of the most important in history was the wheel (Bunch and Hellemans, 2004). However, today's our understanding of technology meaning refers to an utterly different sense from the past for humanity, but in this part, it would be more beneficial to examine today's technology developments and products. Especially over the last fifty years, technology has been well matured to create valuable tools in modern nations, which has been moreover contributing various new opportunities and capabilities as we do not have before. Doubtless, technology is an utter necessity modern life cannot stay away from it since it has a very significant function in our daily lives. In another expression, it has been answering most of the mankind difficulties. Modern technology has encountered massive development in recent years, commencing to its far-reaching use by people of all ages. Advanced technology is frequently considered as a process to increase the effectiveness and efficiency of humanitarian requirements. Modern technology is not the only thing rising at the exponential numbers. The vast of inventions which recently popularized technologies get adopted by users is also growing faster, too. In the modern world, through extensive connectivity, prompt communication, and installed infrastructure operations, innovative ideas and products can expand at the incredible speeds never witnessed before, and this allows a brand-new product to get in the hands of users at the speed of light. Modern technology products adoption and using have changed to a much abbreviated in the last 60 like; microwaves, cell phones, smartphones, social media, tablets, and other irreplaceable inventions from the modern era all show incredible adoption speeds. The bedazzling result is the tablet computer, which went from approximately $0 \%$ to $50 \%$ adoption in five years with modern marketing strategies (Desjardins, 2018).

Figure 5 presents the rate of people's adoption of new products, and technology as a pivotal explanation on the enhancing growth and competitiveness in business. It would be useful to point out while technology has been increasing its significant role in the global competitiveness and that causing expedition in the rate of purchasing at the same parallel, these developments would be a tempting reason for those who want to participate effectively in the global markets.

Figure 5: The rate of People's Adoption of New Products

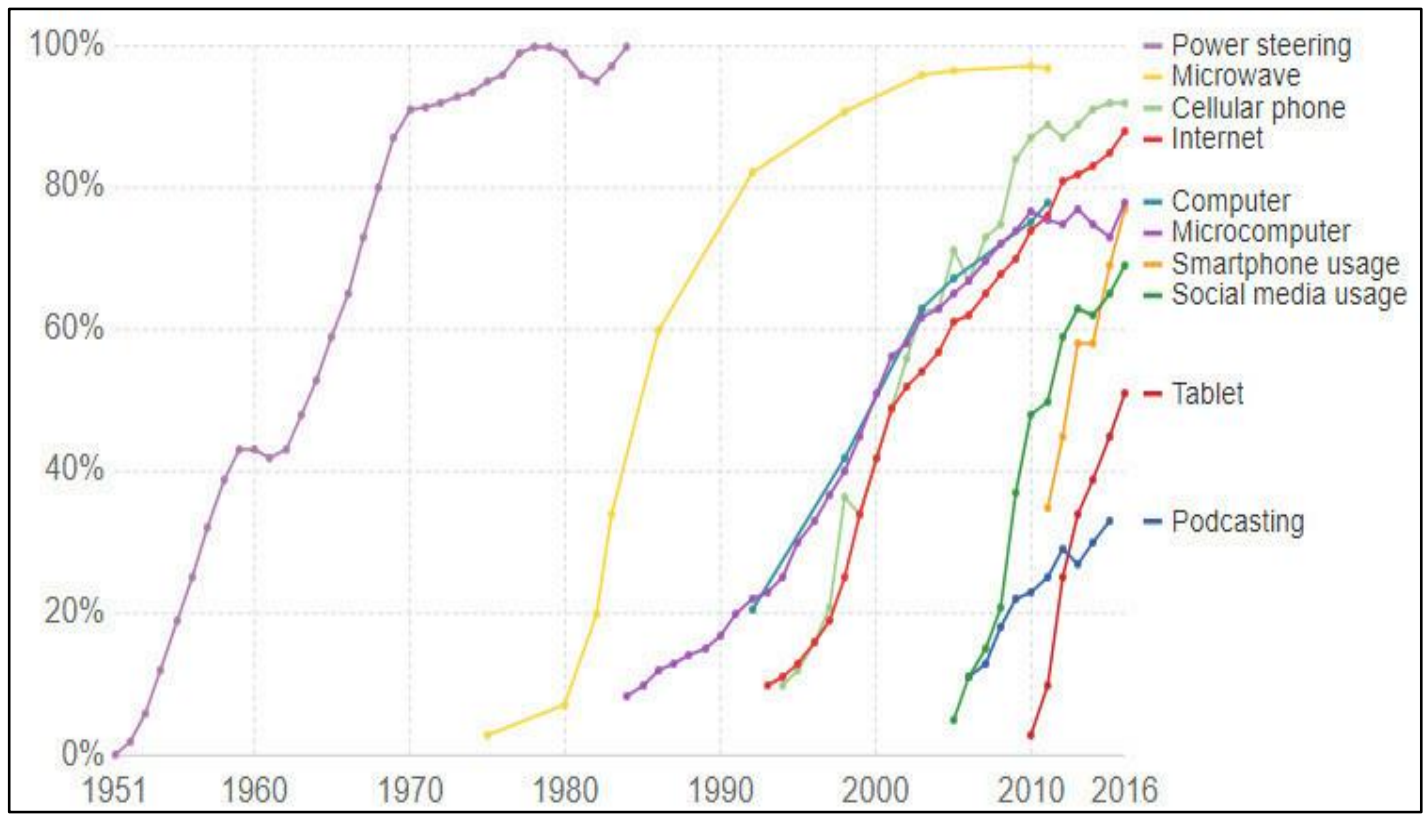

Source: https://www.visualcapitalist.com/rising-speed-technological-adoption/, Accessed at: 12.12.2018.

According to Hatzichronoglou (1997), in the meaning of economic globalization, declared that technology is an outstanding engine in advancing business and raising competitiveness power. Technology-oriented manufacturing companies are building more innovation structure, accessing new business and utilizing existing resources and knowledge to increase productively, causing better salary opportunity for their employees. Therefore, developing countries or who want to reach developing country level must work on their technological 
capability, knowledge, and adaptability to be successful in the more demanding and asymmetric global environment. The qualified employment market, natural resources, economic and political stability, the contemporary educational system, the number of R\&D activities and innovation in the country, are reflected advancement. These actors can cause to differences in development and growth among countries; however, the most significant factor is the technology on which production is based, but it is vital to understand what kind of technology products produce causing the main difference among the countries. It is essential for understanding where the comparative advantages of countries at differing levels of advancement may stand. The classification of "high-tech" and "low-tech" has matured for the examination of economic policy in recent decades. Beginning with the classification of manufacturing businesses right into high-tech, medium-tech and low-tech divisions by the OECD, this separation has been extensively adopted, sometimes with the further different new approach (OECD, 2003).

Table 1: Technology Intensity for Sectors

\begin{tabular}{|ll|}
\hline \multicolumn{1}{|c}{ Technology Level } & ISIC Revision 3 Industry Classification \\
\hline High-technology industries & Aircraft and spacecraft \\
& Pharmaceuticals \\
& Office, accounting and computing machinery \\
\hline Medium-high-technology industries & Radio, TV and communications equipment \\
& Medical, precision and optical instruments \\
& Electrical machinery and apparatus \\
& Motor vehicles, trailers and semi-trailers \\
& Chemicals excluding pharmaceuticals. \\
Medium-low-technology industries & Railroad equipment and transport equipment \\
& Machinery and equipment, \\
& Building and repairing of ships and boats \\
& Rubber and plastics products \\
& Coke, refined petroleum products and nuclear fuel \\
\hline Low-technology industries & Other non-metallic mineral products \\
& Basic metals and fabricated metal products \\
\hline & Manufacturing, n.e.c.; Recycling \\
\hline & Wood, pulp, paper, paper products, printing and publishing \\
\hline & Food products, beverages and tobacco \\
\hline
\end{tabular}

Source: OECD 2007, https://www.oecd.org/sti/inno/48350231.pdf, Accessed at:18.01.2019

The classification into high-tech, medium-tech and low-tech areas are based on the relevant sectors' average share of expenditures for research and development activities. Various scholars have recently criticized the advantage of the low-, medium- and high-tech classifications well as of the aggregative opinion on R\&D intensity (OECD, 2003). The purpose is to investigate the extent to which principles and practice deal with technology regarding structures in the objective or technology rely on four groups of industries have been identified based on the degree of technology intensity, it is worthwhile to mention that two indicators "High tech" and "Medium high tech" have been playing the significant role in the increasing of national welfare and income.

\section{CONCLUSION}

The industrial revolutions has changed and been continiously changing people's life over two hundred years. The revolution 4.0 has redifined all definitons, processes, services and the way of life. The recent revolution highly involves with; data, computational power, connectivity; analytics and Intelligence; human-machine interaction; and digital-to-physical conversion. The new definition of internet-of-things looks to rule the new order of competetiveness in the World. The jobs have been recenly created we never imagined ten years ago. Most jobs have started to disappear we never thought about. Technological innovation and advancement activities have a significant impact on international competitiveness. While most developed countries posses and control high technology production activities, all developing countries have been pushşng to accelerate their economic growth and development by adopting new technologies.

\section{REFERENCES}

Barkey, H. J. (1990). The State and the Industrialization Crisis in Turkey. Boulder: Westview Press.

Bartodziej, C. J. (2016). The Concept of Industry 4.0. Nerlin: Springer Gabler.

Bunch B. \& Hellemans, A. (2004). The History Of Science And Technology. New York: Houghton Mifflin Company.

Davis, N. (2016, 01 19). What is the fourth industrial revolution? World Economic Forum: https://www.weforum.org/agenda/2016/01/whatis-the-fourth-industrial-revolution/ Accessed at: 29.10.2018.

Desjardins, J. (2018). A brief history of technology. weforum: https://www.weforum.org/agenda/2018/02/the-rising-speed-of-technologicaladoption Accessed at: 19.10.2018.

Hatzichronoglou, T. (1997). Revision of the High-Technology Sector and Product Classification. Oxford: Oxford University Press. 
Kagermann, H. (2013). Recommendations for implementing the strategic initiative Industrie 4.0. Munchen: National Academy of Science Engineering.

Kagermann, H., Helbig, J., Hellinger, A., \& Wahlster, W. (2013). Recommendations for implementing the strategic initiative INDUSTRIE 4.0: Securing the future of German manufacturing industry; final report of the Industrie 4.0 Working Group. Forschungsunion.

OECD 2007, https://www.oecd.org/sti/inno/48350231.pdf, Accessed at:18.01.2019

Ramey, K. (2013). What Is Technology - Meaning Of Technology And Its Use. https://www.useoftechnology.com/what-is-technology/ Accessed at: 21.11.2018.

Toffler, A. (1981). The Third Wave. London: Pan Books Ltd.

https://www.businessinsider.de/likelihood-of-your-job-being-taken-over-by-robots-2016-8?r=US\&IR=T, Accessed at: 12.12 .2018 .

http://www.globalskillsummit.com/whitepaper-summary.pdf, Accessed at: 12.12.2018.

https://www.visualcapitalist.com/rising-speed-technological-adoption/, Accessed at: 12.12.2018. 